\title{
Securin promotes the identification of favourable outcome in invasive breast cancer
}

\author{
K Talvinen*,', H Karra', S Hurme², M Nykänen ${ }^{3}$, A Nieminen ${ }^{3}$, J Anttinen ${ }^{3}$, T Kuopio ${ }^{3}$ and P Kronqvist' \\ 'Department of Pathology, University of Turku, Kiinamyllynkatu 10, Turku FIN-20520, Finland; '2Department of Biostatistics, University of Turku, \\ Lemminkäisenkatu I, University of Turku, Turku Fl-200 I4, Finland; ${ }^{3}$ Department of Pathology, Jyväskylä Central Hospital, Keskussairaalantie 19 , \\ Jyväskylä FIN-40620, Finland
}

\begin{abstract}
BACKGROUND: Securin is a recently recognised oncogene with multiple known functions in initiation, progression and cell cycle regulation in several malignant diseases, including breast carcinoma.

METHODS: In this paper, the prognostic value of securin is evaluated by immunohistochemistry in 310 patients diagnosed with invasive breast cancer during a mammographic screening programme in Central Finland. All patients were directed to modern surgical and oncological treatments and were followed up for a maximum of 20 years.

RESULTS: Our results suggest that securin immunopositivity is an independent prognosticator of invasive breast cancer. In our study, securin predicted breast cancer-specific survival among all cases of invasive breast cancer and subgroups divided according to histological type, Ki-67 proliferation status and tumour size. Especially in a multivariate analysis standardised for axillary lymph node status, patient's age and tumour size at the time of diagnosis, securin immunopositivity indicated a I 3. I -fold risk of breast cancer death $(P=0.024)$ among invasive ductal breast carcinomas with low Ki-67 positivity.

CONCLUSION: Our present and previous results suggest that securin could be useful in clinical pathology to intensify the power of the established prognosticators of invasive breast cancer and, especially, to assist in identifying patients with a more favourable outcome than that indicated by Ki-67 alone.

British Journal of Cancer (2009) I 01, I005-1010. doi:I0.1038/sj.bjc.6605237 www.bjcancer.com

Published online 18 August 2009

(c) 2009 Cancer Research UK
\end{abstract}

Keywords: securin; breast cancer; prognosis; proliferation

Despite advances in diagnostics, treatment and overall prognosis of breast cancer, the outcome of individual breast cancer patients may still be unpredictable and relapses occur after several years from primary treatment (Thompson et al, 2008). In recent years, features underlying the heterogeneous behaviour of breast cancer have been addressed with the help of modern methods of molecular pathology and histopathology (van de Vijver et al, 2002; Rakha et al, 2008; Geyer et al, 2009). In several investigations, uncontrolled mitotic activity has been recognised as being among the most important factors influencing breast cancer development and progression (Stuart-Harris et al, 2008; Baak et al, 2009). Uncontrolled aberrant mitotic divisions leading to aneuploidy have been suggested in literature as being one of the most common characteristics of any cancer cell and also with a strong influence on the behaviour of breast cancer (Bharadwaj and $\mathrm{Yu}$, 2004; Kops et al, 2005). This paper reports on the role of securin (pituitary tumour transforming gene, PTTG1) in estimating proliferative activity and prognosis in breast cancer. Securin is an oncogene with a known role in cell cycle regulation and maintenance of chromosomal integrity (Tfelt-Hansen et al, 2006; Bradshaw and Kakar, 2007; Salehi et al, 2008).

Securin was first isolated in rat pituitary tumour cells (Domínguez et al, 1998). Thereafter, securin has been identified

*Correspondence: Dr K Talvinen; E-mail: kattal@utu.fi

Received I 3 May 2009; revised I 3 July 2009; accepted I4 July 2009; published online 18 August 2009 in human tissues with a low expression in normal cells but elevated expressions in proliferating cells of several malignant tumours. To date, securin has been reported to be overexpressed, especially in endocrine-related tumours such as thyroid, breast, ovarian and uterine carcinomas, and also in non-endocrine tumours such as pulmonary and gastrointestinal carcinomas and malignancies of the central nervous system (Shibata et al, 2002; Solbach et al, 2004; Wen et al, 2004; Ogbagabriel et al, 2005; Salehi et al, 2008). Securin is a multidomain and multifunctional protein identified with roles in cell cycle, cellular transformation, tumour development and angiogenesis, although the exact molecular mechanisms of these interactions are for the most part still unrevealed (Salehi et al, 2008). Securin has particularly been suggested to participate in the regulation of chromatid separation during the metaphaseanaphase interface of the cell cycle and to thus take part in maintaining chromosomal stability (Tfelt-Hansen et al, 2006; Bradshaw and Kakar, 2007; Salehi et al, 2008). According to clinical studies, securin overexpression associates with the spread, invasion and metastasis of cancer cells and predicts the outcome of several malignancies (Boelaert et al, 2003; Ramaswamy et al, 2003; Ito et al, 2008). In addition, overexpression of securin has been related to endocrine therapy resistance in breast cancer (Ghayad et al, 2009).

Securin has also been reported to be overexpressed and associated with disease outcome in invasive breast carcinomas (Sáez et al, 1999; Solbach et al, 2004; Ogbagabriel et al, 2005). Our previous paper implied the prognostic value of securin on 
the basis of a cDNA gene expression analysis, and immunohistochemical analyses further suggested that securin might intensify the prognostication of patients with aggressive disease (Talvinen et al, 2008). This paper extends the prognostic value of securin immunohistochemistry in invasive breast cancer on the basis of patient material $(n=310)$ obtained during a mammographic screening programme and followed up for a maximum of 20 years.

\section{MATERIALS AND METHODS}

\section{Patient data}

The study comprises a total of 310 unselected patients diagnosed with invasive breast cancer and treated in the Jyväskylä Central Hospital, Finland, during 1987-1997 when mammographic screening was systematically practised in Central Finland. Treatment of all patients included resection or mastectomy with axillary evacuation, and adjuvant treatment with anti-oestrogen and/or cytostatic drugs depending on the patient's age, hormone receptor status and axillary lymph node status at the time of diagnosis. No pre-operative adjuvant treatment was administered. Patients were followed up for an average of 10.5 post-operative years. Causes of death were based on autopsy reports, death certificates and patient files from the Finnish Cancer Registry. Complete clinical and follow-up data are summarised in Table 1.

\section{Tissue microarrays}

The histological material of each breast cancer patient were arranged in tissue microarrays (TMAs). The representative breast cancer area from routinely formalin-fixed and paraffin-embedded breast cancer blocks from archive material was identified. Two tissue cores (diameter $0.6 \mathrm{~mm}$, min height $5 \mathrm{~mm}$ ), one from the centre and the other from the edge of the representative breast cancer area of each paraffin block, were punched and precisely

Table I Clinicopathological characteristics of patient material $(n=310)$

\begin{tabular}{|c|c|}
\hline \multicolumn{2}{|l|}{ Age at diagnosis (years) } \\
\hline Mean (min to $\max$ ) & $58(49-78)$ \\
\hline \multicolumn{2}{|l|}{ Tumour diameter $(\mathrm{cm})$} \\
\hline Mean (s.d.) & $2.3(1.4)$ \\
\hline \multicolumn{2}{|l|}{ Follow-up time (years) } \\
\hline Mean & 10.5 \\
\hline (Min to $\max$ ) & $(0.2-19.9)$ \\
\hline \multicolumn{2}{|l|}{ Tumour size } \\
\hline Small $(\leqslant 3 \mathrm{~cm})$ & $74 \%(n=229)$ \\
\hline Large $(>3 \mathrm{~cm})$ & $15 \%(n=48)$ \\
\hline \multicolumn{2}{|l|}{ Histological type } \\
\hline Ductal & $81 \%(n=252)$ \\
\hline Lobular & $11 \%(n=33)$ \\
\hline Other types & $7 \%(n=22)$ \\
\hline \multicolumn{2}{|l|}{ Axillary nodal status } \\
\hline Node - & $46 \%(n=142)$ \\
\hline Node + & $45 \%(n=|4|)$ \\
\hline \multicolumn{2}{|l|}{ Ki-67 status } \\
\hline Low $(<10 \%)$ & $42 \%(n=130)$ \\
\hline High $(\geqslant 10 \%)$ & $49 \%(n=153)$ \\
\hline \multicolumn{2}{|c|}{ Causes of death during follow-up } \\
\hline Breast cancer & $18 \%(n=55)$ \\
\hline Other & $20 \%(n=61)$ \\
\hline
\end{tabular}

arranged into three TMA blocks with $238-258$ cores in each, as presented by Kononen et al (1998).

\section{Immunohistochemical methods}

Immunostainings of securin and Ki-67 were applied on $3 \mu \mathrm{m}$ formalin-fixed and paraffin-embedded TMA sections according to the standard procedure using the automated immunostaining machine, LabVision Autostainer 480 (Thermo Fisher Scientific, Fremont, CA, USA). Antigen retrieval was performed in a microwave oven at $99^{\circ} \mathrm{C}$ for 10 (securin) or 15 (Ki-67) min in a citrate buffer (Dako REAL Target Retrieval Solution, Dako, Glostrup, Denmark, S2031, 1:10). Antibodies were applied at concentrations of 1:50 (securin, clone DCS-280, ab3305, Abcam, Cambridge, UK) and 1:100 (Ki-67, 18-0192, Zymed, Invitrogen, Carlsbad, CA, USA). Detection was performed using a PowerVision + polymer Kit according to standard protocols (DPVB $+110 \mathrm{HRP}$, ImmunoVision Technologies, Vision BioSytems, Norwell, MA, USA) with diaminobenzidine as chromogen. All malignant cells of each tissue cylinder were counted. Positively stained securin and Ki-67 nuclei were registered as a fraction (\%) of the number of tumour cells. In our previous paper, we presented intraclass correlation coefficients for intra- and interobserver reproducibilities of securin and Ki-67 immunoevaluations (ICC $0.51-0.96$ ) (Talvinen et al, 2008).

\section{Statistical analysis}

To explore the prognostic value of securin and $\mathrm{Ki}-67$, we elaborated a threshold based on follow-up information of the patient material by screening with univariate analyses and selecting points of strongest prognostic value. Selected cut-off points were confirmed by receiver operating characteristic analysis. To evaluate the potential of securin to intensify the value of Ki-67 in breast cancer prognostication, we analysed all possible combinations of low and high expressions of both securin and Ki67 immunopositivity by forming four classes of patients: low securin and low Ki-67, high securin and low Ki-67, low securin and high Ki-67, and high securin and high Ki-67.

The present analysis allowed us to estimate the consistency related to the histological TMA method by comparing results from tissue punches representing different areas of the specimen, one punch from the centre and another from the periphery of the tumour. Comparison of immunopositivity of the central and peripheral tumour areas showed moderate consistency (ICC 0.737 for securin and 0.887 for $\mathrm{Ki}-67)$. Moreover, McNemar's test of marginal homogeneity $(P=0.63$ and $P=0.45$ for securin and Ki-67, respectively) and kappa coefficients $(\kappa=0.59$ and $\kappa=0.69$ for securin and Ki-67, respectively) showed concordance between central and peripheral tissue cores. The observed acceptable consistencies between the results of central and peripheral tumour areas allowed us to apply for final prognostic analyses either the mean of the results of the two tissue cores ( $65 \%$ of cases) or a single observation. A single observation was used if only one tissue core was representative of cancer cells.

Survival analysis was performed to investigate the prognostic value of securin and the association between securin and Ki-67 in evaluating breast cancer outcome. The cumulative percentages for breast cancer-specific mortality were estimated using the KaplanMeier technique and the differences between categorised values were tested using the log-rank test. Differences between categories were quantified by calculating hazard ratios (HRs) with $95 \%$ confidence intervals (95\% CIs) using Cox's regression models. Cox's regression models with multiple explanatory variables were used to adjust the results for axillary lymph node status classified as node-positive and node-negative cases, with patient's age and tumour size as continuous variables. An adjusted analysis was made separately for securin, Ki-67 and the variable established by the combination of the two. Patients with missing data were 
Table 2 Summary of mean fractions (\%) and standard deviations (in parentheses) of securin and Ki-67 immunopositive nuclei

\begin{tabular}{lcc}
\hline & Securin & Ki-67 \\
\hline All & $6.1(6.8)$ & $15.0(14.2)$ \\
Ki-67, $<10 \%$ & $3.3(4.1)$ & $4.5(2.6)$ \\
Ki-67, $\geqslant 10 \%$ & $8.6(7.3)$ & $24.0(14.0)$ \\
IDC & & \\
Ki-67, $<10 \%$ & $6.4(6.9)$ & $16.0(14.8)$ \\
Ki-67, $\geqslant 10 \%$ & $3.5(4.3)$ & $4.8(2.5)$ \\
\hline
\end{tabular}

The results are based on all patients with invasive breast carcinoma $(n=3 \mid 0)$ and on subgroups divided according to invasive ductal histology (IDC) and Ki-67 immunopositivity (low, <10\%; high, $\geqslant 10 \%$ )

excluded from analyses. $P$-values less than 0.05 were considered to be statistically significant. All statistical computations were performed using SAS System for Windows, Version 9.1.3 and SAS Enterprise Guide 4.1. (SAS Institute Inc., Cary, NC, USA).

\section{RESULTS}

Table 2 summarises the results of securin and Ki-67 immunohistochemistry in 310 cases of invasive breast cancer and in patient subgroups divided according to tumour histology and Ki-67 status. The observed fraction of securin immunopositivity was systematically lower than that of Ki-67 throughout all cases and prognostic subgroups. Screening with univariate survival analyses and selecting points of strongest prognostic value set an optimal cut-off point at $1.5 \%$ for securin immunopositivity. This cut-off point produced two patient groups, which, with the highest statistical significance, identified patients who were alive with or who died of breast cancer during the follow-up period. Receiver operating characteristic analysis of securin immunohistochemistry validated the selected cut-off point. The same methods confirmed the established threshold of $10 \%$ immunopositivity as the optimal cut-off point for Ki-67 in our study (Tavassoli and Devilee, 2003, p 19).

Figure 1 shows the potential of securin to separate the patients into groups of favourable and unfavourable outcome of breast cancer on the basis of a cut-off point of $1.5 \%$ immunopositivity $(P=0.004)$. Similarly, the prognostic significance of securin was shown in subgroups of invasive ductal histology $(P=0.010)$, and with small and large tumour size $(P=0.034$ and $P=0.033$ for tumour diameters $\leqslant 3 \mathrm{~cm}$ and $>3 \mathrm{~cm}$, respectively). The results of Cox's univariate survival analyses are interpreted as a comparison of the survival between groups of patients associated with securin and Ki-67 immunopositivity above and below the determined cutoff points at 1.5 and $10 \%$, respectively. On the basis of an analysis of all cases and subgroups of ductal histology of breast cancer, securin predicted the survival of disease with statistical significance (Table 3). In comparison with the prognostic values of securin and Ki-67, univariate Cox's survival analysis for securin indicated a 2.9 -fold $(P=0.006,95 \%$ CI $1.3-6.0)$ and for Ki-67 a 2.4-fold risk of breast cancer death $(P=0.004,95 \%$ CI $1.3-4.5)$. In a combination of securin and $\mathrm{Ki}-67$, the observed risk of breast cancer death was 5.8-fold (securin $\geqslant 1.5$ and $\mathrm{Ki}-67 \geqslant 10 \%$ vs securin $<1.5$ and $\mathrm{Ki}-67<10 \%, P=0.004,95 \%$ CI $1.8-18.9)$. In addition, when compared, the high to low securin immunopositivity risk for breast cancer death was 2.7 -fold for patients with small and 3.6-fold for patients with large tumour size $(P=0.042$, $95 \%$ CI $1.0-7.0$ and $P=0.046,95 \%$ CI $1.0-12.4$, respectively).

When the data of 310 breast cancer cases were adjusted for nodal status, patient's age and tumour size, securin immunopositivity still seemed to be a statistically significant predictor for outcome of invasive breast cancer (Table 4). In this analysis, the

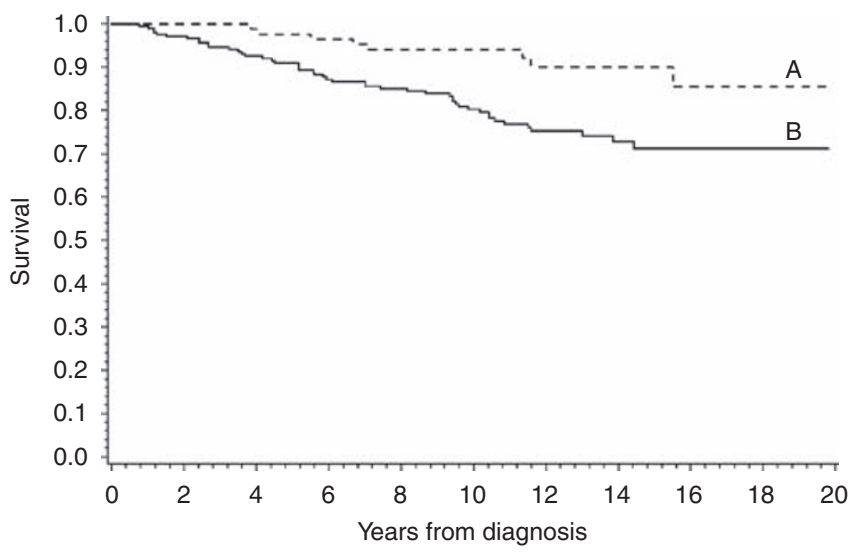

Figure I Kaplan-Meier curves of breast cancer survival based on securin immunohistochemistry in 310 breast cancer patients. Securin immunohistochemistry (positivity $<1.5 \%$ (A) vs $\geqslant 1.5 \%$ (B) of cancer cell nuclei) distinguishes patients with a different outcome of disease $(P=0.004)$.

Table 3 Summary of Cox's univariate analyses on securin immunopositivity performed in invasive breast carcinomas and in subgroups divided according to invasive ductal histology (IDC) and Ki-67 immunopositivity (low, <10\%; high, $\geqslant 10 \%$ )

\begin{tabular}{|c|c|c|c|c|}
\hline & $n$ & $P$ & HR & 95\% Cl \\
\hline $\begin{array}{l}\text { All } \\
\quad \mathrm{Ki}-67<10 \% \\
\mathrm{Ki}-67 \geqslant 10 \%\end{array}$ & $\begin{array}{l}310 \\
130 \\
153\end{array}$ & $\begin{array}{l}0.006 \\
0.057 \\
0.523\end{array}$ & 2.9 & $1.3-6.0$ \\
\hline $\begin{array}{l}\text { IDC } \\
\quad \mathrm{Ki}-67<10 \% \\
\mathrm{Ki}-67 \geqslant 10 \%\end{array}$ & $\begin{array}{l}252 \\
101 \\
134\end{array}$ & $\begin{array}{l}0.014 \\
0.064 \\
0.626\end{array}$ & 2.9 & $1.2-6.8$ \\
\hline
\end{tabular}

The results are based on the optimal cut-point determined at $1.5 \%$ of securin immunopositivity, derived from analysis of breast cancer-specific survival of the patient data.

Table 4 Summary of multivariate Cox's regression analyses of securin immunoexpression performed in invasive breast carcinomas and in subgroups divided according to invasive ductal histology (IDC) and Ki-67 immunopositivity (low, <10\%; high, $\geqslant 10 \%$ )

\begin{tabular}{lcccc}
\hline & $\boldsymbol{n}$ & $\boldsymbol{P}$ & $\mathbf{H R}$ & $\mathbf{9 5 \%} \mathbf{~ C l}$ \\
\hline All & 257 & 0.028 & 2.3 & $1.1-5.0$ \\
$\mathrm{Ki}-67<10 \%$ & 106 & 0.031 & 5.1 & $1.2-22.7$ \\
$\mathrm{Ki}-67 \geqslant 10 \%$ & 134 & 0.617 & & \\
$\mathrm{IDC}$ & 211 & 0.051 & & \\
$\mathrm{Ki}-67<10 \%$ & 84 & 0.024 & 13.1 & $1.4-121.3$ \\
$\mathrm{Ki}-67 \geqslant 10 \%$ & 118 & 0.719 & & \\
\hline
\end{tabular}

The results are based on the optimal cut-point determined at $1.5 \%$ of securin immunopositivity, derived from analysis of breast cancer-specific survival of the patient data. Axillary lymph node status, patient's age and tumour size at the time of diagnosis were used as covariates in multivariate analyses.

observed HR of breast cancer death was 2.3 for securin $(P=0.028$, $95 \%$ CI $1.1-5.0)$. As expected, nodal status $(P=0.0004)$ and tumour size $(P<0.0001)$ were also significant predictors of breast cancer death. The corresponding analysis of $\mathrm{Ki}-67$ indicated a similar prognostic potential, although statistical significance was not quite attained in our study $(P=0.058, \mathrm{HR} 1.9)$. The highest prognostic value was associated with the combination of securin and $\mathrm{Ki}-67$, which predicted a 4.3 -fold risk for breast cancer death 
in our study $(P=0.017,95 \%$ CI $1.3-14.2)$. In addition, in the subgroup having low proliferative activity (Ki-67<10\%), securin predicted a 5.1 -fold risk of breast cancer death $(P=0.031,95 \% \mathrm{CI}$ $1.2-22.7)$. Further analysis of patients with low Ki-67 positivity and invasive ductal histology associated securin immunohistochemistry with a 13.1-fold risk of breast cancer death $(P=0.024$, $95 \%$ CI 1.4-121.3). Similarly, securin immunopositivity predicted the disease outcome among patients with large tumour size ( $>3 \mathrm{~cm}$ in diameter) when adjusted for patient's age and nodal status $(P=0.040$, HR $3.8,95 \%$ CI $1.1-13.7)$.

\section{DISCUSSION}

Securin is a recently recognised oncogene with multiple known functions in the tumourigenesis and progression of malignant diseases, especially in the regulation of chromosome integrity in cell proliferation. In breast cancer research, knowledge about securin is fast accumulating, but to date, there are no published prognostic studies on securin in invasive breast cancer patients with long-term follow-up.

Our results suggest that securin immunohistochemistry is an independent prognosticator of invasive breast cancer. This finding is in concordance with our previous paper comprising a small sample size of aggressive breast carcinomas with a high proliferation rate (Talvinen et al, 2008). In this paper on 310 breast cancer patients with a long-term follow-up, low securin immunopositivity indicated a favourable course of disease, especially in association with low Ki-67 immunopositivity. In our results, the combination of high immunopositivity for both securin and $\mathrm{Ki}-67$ indicated a 4.3-fold risk of breast cancer death as compared with the prognostic value of low securin and Ki-67, suggesting that securin in combination with $\mathrm{Ki}-67$ enhances the prognostic information derived from cell proliferation. In the light of our results, securin may prove to be a valuable prognostic factor for clinical pathology, although the present data do not yet allow for testing of the possible prognostic value of securin in relation to the gold standard of breast cancer prognostics, the Nottingham Prognostic Index (Elston and Ellis, 1991).

According to literature, securin is involved in the regulation of cell cycle as a mitotic check-point gene, functioning in the metaphase-anaphase transfer (Hagting et al, 2002). Securin is critical for genetic stability, as it inhibits premature sister chromatid separation. In detail, during metaphase, cohesin binds sister chromatids and degradation by separase is necessary to enable sister chromatid separation at anaphase (Ciosk et al, 1998; Nasmyth, 2005). According to present knowledge, securin is involved in arresting metaphase by binding to separase, preventing cohesin degradation and thus blocking chromatid separation (Waizenegger et al, 2002; Nasmyth, 2005). Despite this biological understanding of the function of securin during a normal cell cycle, the role of securin in the proliferation of malignant cells is still unsettled. Some investigations suggest that securin overexpression could reduce cell proliferation by arresting mitosis (Yu et al, 2000). Others have speculated that securin could function in cell proliferation through the induction of apoptosis and delay of mitosis (Akino et al, 2005). Inhibition of sister chromatid separation, in turn, suggests that securin is responsible for uneven chromatid separation and induction of aneuploidy in tumourigenesis and tumour progression (Tfelt-Hansen et al, 2006; Vlotides et al, 2007; Salehi et al, 2008). Available clinical studies, however, demonstrate a strong correlation between securin expression and cell proliferation in different malignancies (Heaney et al, 2002; Tsai et al, 2005; Filippella et al, 2006; Genkai et al, 2006; Zhu et al, 2006).

As a proliferation marker, securin clearly differs from established markers of cell proliferation in clinical pathology. The established proliferation markers, Ki-67 and proliferating cell nuclear antigen (PCNA), are expressed in all phases of the cell cycle (Takasaki et al, 1981; Guillaud et al, 1989; van Oijen et al, 1998). In comparison with these, securin concentrates on a specific phase of the cell cycle, the expression gradually increasing during the S phase with a peak at G2/M (Yu et al, 2000; Chen et al, 2005; Chao and Liu, 2006). According to many investigations, specific fractions of the cell cycle might provide relevant information on the behaviour of different malignancies. Therefore, markers of selected phases of the cell cycle could prove beneficial for individual breast cancer patients in intensifying the value of established proliferation markers (Heidebrecht et al, 1997; Rudolph et al, 1999, 2001). Prognostication of breast cancer is at the moment based on Ki-67 immunohistochemistry, which has been proven to have strong prognostic correlations (Bouzubar et al, 1989; Veronese et al, 1993). Our paper suggests that the application of securin alone or in combination with other proliferation markers could contribute to the prognostication of invasive breast cancer.

The observed average level of securin immunopositivity in our present results differs from that of our previous study (Talvinen et al, 2008). The obvious explanations lie in the different patient selection procedure and histological material. The present patient data comprise mammographic screening cases characterised by early cancer detection, modern diagnostic and therapeutic methods, and long-term follow-up. Moreover, the type of histological material is an important feature in the observed securin expression. At present, TMAs are also established for staining for cell proliferation (Hoos et al, 2001; García et al, 2003; Couvelard et al, 2009). However, some publications address the possible influence of field selection of TMAs on the observed immunopositivity, especially with regard to uneven staining and expression patterns (Gillett et al, 2000; Wärnberg et al, 2008; Couvelard et al, 2009). This is of special interest with regard to the expression of proliferation markers, which is, according to many investigators, concentrated in 'hot spots', that is, the most cellular and invasive front at the periphery of the tumour (Jannink et al, 1995; Beliën et al, 1999, Salminen et al, 2005). Thus, TMA punches do not necessarily represent the most proliferative tumour area and, therefore, the highest securin and Ki-67 expression of the tumour might not be evaluated in this study. This does hamper comparison between reports but does not, however, influence the prognostic conclusions based on a single study with consistent histological and immunohistochemical methods.

In summary, this paper introduces securin as a prognostic factor of breast cancer-specific survival, independent of patient's age, nodal status and tumour size. In combination with Ki-67 immunohistochemistry, securin further intensified the prognostic value of cell proliferation. Although the cut-off point may not directly be applicable to clinical material in whole sections, our results on TMA suggest that minimal or absent securin immunopositivity could indicate a more favourable outcome of disease than that concluded from Ki-67 immunopositivity alone. Securin is a recently published oncogene with multiple functions in tumourigenesis and progression, invasion, and metastasis of malignant disease, and, therefore, further investigations are needed to evaluate the possible prognostic and therapeutic applications of securin in treatment decisions of individual breast cancer patients.

\section{ACKNOWLEDGEMENTS}

The authors thank Mr Hans Helenius from the Department of Biostatistics, University of Turku, Turku, Finland for his valuable help. This study was supported by the Turku University Central Hospital. The research has the approval of the Ethics Committee of the University of Turku, Turku, Finland. 


\section{REFERENCES}

Akino K, Akita S, Mizuguchi T, Takumi I, Yu R, Wang XY, Rozga J, Demetriou AA, Melmed S, Ohtsuru A, Yamashita S (2005) A novel molecular marker of pituitary tumor transforming gene involves in a rat liver regeneration. J Surg Res 129: $142-146$

Baak JP, Gudlaugsson E, Skaland I, Guo LH, Klos J, Lende TH, Søiland H, Janssen EA, Zur Hausen A (2009) Proliferation is the strongest prognosticator in node-negative breast cancer: significance, error sources, alternatives and comparison with molecular prognostic markers. Breast Cancer Res Treat 115: $241-254$

Beliën JA, van Diest PJ, Baak JP (1999) Relationships between vascularization and proliferation in invasive breast cancer. I Pathol 189: 309-318

Bharadwaj R, Yu H (2004) The spindle checkpoint, aneuploidy, and cancer. Oncogene 23: 2016-2027

Boelaert K, McCabe CJ, Tannahill LA, Gittoes NJ, Holder RL, Watkinson JC, Bradwell AR, Sheppard MC, Franklyn JA (2003) Pituitary tumor transforming gene and fibroblast growth factor-2 expression: potential prognostic indicators in differentiated thyroid cancer. J Clin Endocrinol Metab 88: $2341-2347$

Bouzubar N, Walker KJ, Griffiths K, Ellis IO, Elston CW, Robertson JF, Blamey RW, Nicholson RI (1989) Ki67 immunostaining in primary breast cancer: pathological and clinical associations. $\mathrm{Br} J$ Cancer 59: $943-947$

Bradshaw C, Kakar SS (2007) Pituitary tumor transforming gene: an important gene in normal cellular functions and tumorigenesis. Histol Histopathol 22: $219-226$

Chao JI, Liu HF (2006) The blockage of survivin and securin expression increases the cytochalasin B-induced cell death and growth inhibition in human cancer cells. Mol Pharmacol 69: 154-164

Chen Z, Merta PJ, Lin NH, Tahir SK, Kovar P, Sham HL, Zhang H (2005) A-432411, a novel indolinone compound that disrupts spindle pole formation and inhibits human cancer cell growth. Mol Cancer Ther 4: $562-568$

Ciosk R, Zachariae W, Michaelis C, Shevchenko A, Mann M, Nasmyth K (1998) An ESP1/PDS1 complex regulates loss of sister chromatid cohesion at the metaphase to anaphase transition in yeast. Cell 93: $1067-1076$

Couvelard A, Deschamps L, Ravaud P, Baron G, Sauvanet A, Hentic O, Colnot N, Paradis V, Belghiti J, Bedossa P, Ruszniewski P (2009) Heterogeneity of tumor prognostic markers: a reproducibility study applied to liver metastases of pancreatic endocrine tumors. Mod Pathol 22: $273-281$

Domínguez A, Ramos-Morales F, Romero F, Rios RM, Dreyfus F, Tortolero M, Pintor-Toro JA (1998) hpttg, a human homologue of rat pttg, is overexpressed in hematopoietic neoplasms. Evidence for a transcriptional activation function of hPTTG. Oncogene 17: $2187-2193$

Elston CW, Ellis IO (1991) Pathological prognostic factors in breast cancer. I. The value of histological grade in breast cancer: experience from a large study with long-term follow-up. Histopathology 19: $403-410$

Filippella M, Galland F, Kujas M, Young J, Faggiano A, Lombardi G, Colao A, Meduri G, Chanson P (2006) Pituitary tumour transforming gene (PTTG) expression correlates with the proliferative activity and recurrence status of pituitary adenomas: a clinical and immunohistochemical study. Clin Endocrinol (Oxf) 65: 536-543

García JF, Camacho FI, Morente M, Fraga M, Montalbán C, Alvaro T, Bellas C, Castaño A, Díez A, Flores T, Martin C, Martinez MA, Mazorra F, Menárguez J, Mestre MJ, Mollejo M, Sáez AI, Sánchez L, Piris MA, Spanish Hodgkin Lymphoma Study Group (2003) Hodgkin and ReedSternberg cells harbor alterations in the major tumor suppressor pathways and cell-cycle checkpoints: analyses using tissue microarrays. Blood 101: $681-689$

Genkai N, Homma J, Sano M, Tanaka R, Yamanaka R (2006) Increased expression of pituitary tumor-transforming gene (PTTG)-1 is correlated with poor prognosis in glioma patients. Oncol Rep 15: 1569-1574

Geyer FC, Marchio C, Reis-Filho IS (2009) The role of molecular analysis of breast cancer. Pathology 41: $77-88$

Ghayad SE, Vendrell JA, Bieche I, Spyratos F, Dumontet C, Treilleux I, Lidereau R, Cohen PA (2009) Identification of TACC1, NOV, and PTTG1 as new candidate genes associated with endocrine therapy resistance in breast cancer. J Mol Endocrinol 42: 87-103

Gillett CE, Springall RJ, Barnes DM, Hanby AM (2000) Multiple tissue core arrays in histopathology research: a validation study. J Pathol 192: $549-553$
Guillaud P, du Manoir S, Seigneurin D (1989) Quantification and topographical description of Ki-67 antibody labelling during the cell cycle of normal fibroblastic (MRC-5) and mammary tumour cell lines (MCF-7). Anal Cell Pathol 1: 25-39

Hagting A, Den Elzen N, Vodermaier HC, Waizenegger IC, Peters JM, Pines J (2002) Human securin proteolysis is controlled by the spindle checkpoint and reveals when the APC/C switches from activation by Cdc20 to Cdh1. J Cell Biol 157: $1125-1137$

Heaney AP, Fernando M, Melmed S (2002) Functional role of estrogen in pituitary tumor pathogenesis. J Clin Invest 109: 277-283

Heidebrecht HJ, Buck F, Steinmann J, Sprenger R, Wacker HH, Parwaresch R (1997) p100: a novel proliferation-associated nuclear protein specifically restricted to cell cycle phases S, G2 and M. Blood 1: 226-233

Hoos A, Urist MJ, Stojadinovic A, Mastorides S, Dudas ME, Leung DH, Kuo D, Brennan MF, Lewis JJ, Cordon-Cardo C (2001) Validation of tissue microarrays for immunohistochemical profiling of cancer specimens using the example of human fibroblastic tumors. Am J Pathol 158: $1245-1251$

Ito T, Shimada Y, Kan T, David S, Cheng Y, Mori Y, Agarwal R, Paun B, Jin Z, Olaru A, Hamilton JP, Yang J, Abraham JM, Meltzer SJ, Sato F (2008) Pituitary tumor-transforming 1 increases cell motility and promotes lymph node metastasis in esophageal squamous cell carcinoma. Cancer Res 68: 3214-3224

Jannink I, van Diest PJ, Baak JP (1995) Comparison of the prognostic value of four methods to assess mitotic activity in 186 invasive breast cancer patients: classical and random mitotic activity assessments with correction for volume percentage of epithelium. Hum Pathol 26: $1086-1092$

Kononen J, Bubendorf L, Kallioniemi A, Bärlund M, Schraml P, Leighton S, Torhorst J, Mihatsch MJ, Sauter G, Kallioniemi OP (1998) Tissue microarrays for high-throughput molecular profiling tumor of specimens. Nat Med 4: 844-847

Kops GJ, Weaver BA, Cleveland DW (2005) On the road to cancer: aneuploidy and the mitotic checkpoint. Nat Rev Cancer 5: 773-785

Nasmyth K (2005) How do so few control so many? Cell 120: 739-746

Ogbagabriel S, Fernando M, Waldman FM, Bose S, Heaney AP (2005) Securin is overexpressed in breast cancer. Mod Pathol 18: 985-990

Rakha FA, Reis-Filho JS, Ellis IO (2008) Impact of basal-like breast carcinoma determination for a more specific therapy. Pathobiology 75: $95-103$

Ramaswamy S, Ross KN, Lander ES, Golub TR (2003) A molecular signature of metastasis in primary solid tumors. Nat Genet 33: 49-54

Rudolph P, Alm P, Heidebrecht H-J, Bolte H, Ratjen V, Baldetorp B, Fernö M, Olsson H, Parwaresch R (1999) Immunologic proliferation marker Ki-S2 as prognostic indicator for lymph node-negative breast cancer. J Natl Cancer Inst 91: 271-278

Rudolph P, Alm P, Olsson H, Heidebrecht HJ, Fernö M, Baldetorp B, Parwaresch R (2001) Concurrent overexpression of p53 and c-erbB-2 correlates with accelerated cycling and concomitant poor prognosis in node-negative breast cancer. Hum Pathol 32: 311 - 319

Sáez C, Japón MA, Ramos-Morales F, Romero F, Segura DI, Tortolero M, Pintor-Toro JA (1999) hpttg is over-expressed in pituitary adenomas and other primary epithelial neoplasias. Oncogene 18: 5473-5476

Salehi F, Kovacs K, Scheithauer BW, Lloyd RV, Cusimano M (2008) Pituitary tumor-transforming gene in endocrine and other neoplasms: a review and update. Endocr Relat Cancer 15: 721 - 743

Salminen E, Palmu S, Vahlberg T, Roberts PJ, Söderström KO (2005) Increased proliferation activity measured by immunoreactive Ki67 is associated with survival improvement in rectal/recto sigmoid cancer. World J Gastroenterol 11: 3245-3249

Shibata Y, Haruki N, Kuwabara Y, Nishiwaki T, Kato J, Shinoda N, Sato A, Kimura M, Koyama H, Toyama T, Ishiguro H, Kudo J, Terashita Y, Konishi S, Fujii Y (2002) Expression of PTTG (pituitary tumor transforming gene) in esophageal cancer. Jpn J Clin Oncol 32: $233-237$

Solbach C, Roller M, Fellbaum C, Nicoletti M, Kaufman M (2004) PTTG mRNA expression in primary breast cancer: a prognostic marker for lymph node invasion and tumor recurrence. Breast 13: $80-81$

Stuart-Harris R, Caldas C, Pinder SE, Pharoah P (2008) Proliferation markers and survival in early breast cancer: a systematic review and meta-analysis of 85 studies in 32825 patients. Breast 17: $323-334$

Takasaki Y, Deng JS, Tan EM (1981) A nuclear antigen associated with cell proliferation and blast transformation. J Exp Med 154: 1899-1909 
Talvinen K, Tuikkala J, Nevalainen O, Rantanen A, Hirsimäki P, Sundström J, Kronqvist P (2008) Proliferation marker securin identifies favourable outcome in invasive ductal breast cancer. $\mathrm{Br}$ J Cancer 99: $335-340$

Tavassoli FA, Devilee P (eds) World Health Organization Classification of Tumours. Pathology and Genetics of Tumours of the Breast and Female Genital Organs. IARC Press: Lyon, p 19

Tfelt-Hansen J, Kanuparthi D, Chattopadhyay N (2006) The emerging role of pituitary tumor transforming gene in tumorigenesis. Clin Med Res 4: $130-137$

Thompson A, Brennan K, Cox A, Gee J, Harcourt D, Harris A, Harvie M, Holen I, Howell A, Nicholson R, Steel M, Streuli C (2008) Evaluation of the current knowledge limitations in breast cancer research: a gap analysis. Breast Cancer Res 10: R26

Tsai SJ, Lin SJ, Cheng YM, Chen HM, Wing LY (2005) Expression and functional analysis of pituitary tumor transforming gene-1 [corrected] in uterine leiomyomas. J Clin Endocrinol Metab 90: 3715-3723

van de Vijver MJ, He YD, van't Veer LJ, Dai H, Hart AA, Voskuil DW, Schreiber GJ, Peterse JL, Roberts C, Marton MJ, Parrish M, Atsma D, Witteveen A, Glas A, Delahaye L, van der Velde T, Bartelink H, Rodenhuis S, Rutgers ET, Friend SH, Bernards R (2002) A geneexpression signature as a predictor of survival in breast cancer. $N$ Engl J Med 347: 1999-2009 van Oijen MG, Medema RH, Slootweg PJ, Rijksen G (1998) Positivity of the proliferation marker Ki-67 in noncycling cells. Am J Clin Pathol 110: $24-31$ Veronese SM, Gambacorta M, Gottardi O, Scanzi F, Ferrari M, Lampertico $P$ (1993) Proliferation index as a prognostic marker in breast cancer. Cancer 71: 3926 - 3931

Vlotides G, Eigler T, Melmed S (2007) Pituitary tumor-transforming gene: physiology and implications for tumorigenesis. Endocr Rev 28: 165-186

Waizenegger I, Giménez-Abián JF, Wernic D, Peters JM (2002) Regulation of human separase by securin binding and autocleavage. Curr Biol 12: $1368-1378$

Wen CY, Nakayama T, Wang AP, Nakashima M, Ding YT, Ito M, Ishibashi H, Matsuu M, Shichijo K, Sekine I (2004) Expression of pituitary tumor transforming gene in human gastric carcinoma. World $J$ Gastroenterol 10: $481-483$

Wärnberg F, Amini RM, Goldman M, Jirström K (2008) Quality aspects of the tissue microarray technique in a population-based cohort with ductal carcinoma in situ of the breast. Histopathology 53: 642-649

Yu R, Ren SG, Horwitz GA, Wang Z, Melmed S (2000) Pituitary tumor transforming gene (PTTG) regulates placental JEG-3 cell division and survival: evidence from live cell imaging. Mol Endocrinol 14: 1137-1146

Zhu X, Mao Z, Na Y, Guo Y, Wang X, Xin D (2006) Significance of pituitary tumor transforming gene 1 (PTTG1) in prostate cancer. Anticancer Res 26: $1253-1259$ 